\title{
The Relationship of Eye-foot Coordination with Football Skill: A Correlation Study in Young Football Player
}

\author{
Razali Razali*1, Myrza Akbari² \\ ${ }^{1}$ Department of Physical Education, Health and Recreation, Faculty of Teacher Training and Education, Universitas \\ Syiah Kuala, Banda Aceh 23111, Indonesia; \\ ${ }^{2}$ Department of Physical Education, Faculty of Teacher Training and Education, Universitas Samudra, Langsa \\ 24416, Indonesia \\ ${ }^{*}$ Corresponding author. email: razali.ismail@unsyiah.ac.id
}

\begin{abstract}
Football skills are one of the fundamental aspectsthat football players must possess. In addition, to support football skills, football players must be equipped with abilities in good physical condition. Based on previous research studies, movement in football is dominated by dynamic movements, so that movement Coordination is one aspect of physical condition that is important in supporting football skills. This study aimed to determine the relationship between variables, eye-foot coordination, and football skills. The approach taken in this research is quantitative, and the type of research is correlated. The population in this study is the Junior Players of the Persati Aceh Tamiang Club,totalling 36 athletes (total sampling). The data collection techniques are as follows: (1) eye-foot coordination using the "Football Wall Volley Test", (2) football skills are measured using the "David Lee test". Data analysis was carried out using a simple correlation analysis technique and multiple correlations. The conclusions obtained based on the results of data analysis are: (1) there is a significant relationship between eye-foot coordination and football skills. $(r=0.74)$, and eyefoot coordination contributes $53,29 \%$ to football skills
\end{abstract}

Keywords: Football, Eye-foot, Coordination.

\section{INTRODUCTION}

Every aspect of football-playing skills requires other skills to support good technical quality. In addition to players' talent that will affect the quality of playing skills, many factors still need to be trained and are the result of training as a supporting factor [1].

The coordination skill that football players need is eye-foot coordination because the eyes are the centre of view to see around the field, and the feet act as executors of the ball at the time of passing [2]. Exercises that can improve eye-foot coordination include variations in footsteps combined with the direction of the player's eyes, trained to align vision with foot movements. The football game which is dominated by the use of the feet, makes the eye-foot coordination aspect play a vital role during the game [3].

Improving football skills is much influenced by physical and technical abilities, which are a basis that every football player must-have. One of every player's physical abilities in carrying out dribbling movements is coordination. Coordination is the ability to integrate various movements into a single, effective and harmonious movement. Coordination is not a physical condition that stands alone but is a combination of various abilities of other biometer components [4]

Eye-foot coordination is very important to be able to carry out twisting dribbling movements or movements to change direction suddenly on several sides to pass the opponent. Football players who have good eye-foot coordination will make a maximum contribution to dribbling in football games [5].

Coordination is closely related to speed, strength, endurance, and flexibility and is essential for learning and perfecting techniques and tactics. Good eye-foot coordination in dribbling makes it difficult for opponents to win the ball because it is always in control and close to the feet of the player who is dribbling. Football players who have eye-foot coordination will 
appear calmer in dribbling. Dribbling movements can be more varied so that they can trick opponents [6].

A skill, referring to the pattern of movement, an appearance that is oriented to time and space, has various levels of complexity. The criteria to meet the coordination requirements are (1) difficulty level: a skill or appearance that is oriented to easy or difficult. Cyclical skills are less complex and easier to acquire when compared to a silky, (2) performance accuracy: a movement may be performed with high precision during a match. Usually, a form of skill that is carried out with high accuracy is the efficiency of movement from physiology and biomechanics, (3) the length of acquisition: the complexity of skill is also related to the time it takes to acquire it. Individuals who have good coordination will more quickly acquire a skill than individuals who lack coordination [7].

Coordination is the ability to perform movements with various difficulty levels efficiently, quickly and with full accuracy [8]. Coordination is one of the most important components of physical condition and is needed in almost all sports, especially football. Athletes with good coordination will easily and quickly perform various skills. By having good coordination, athletes will change one movement pattern to another quickly. Coordination can also train the balance of the right and left brains.

\section{METHODS}

This research uses a quantitative approach, and the type of research is correlational. This study aims to calculate the relationship between two variables. The design of this study is divided into two groupings, namely the eye-foot coordination test as (variable X1) and the test of playing football skills as (variable Y), variable $\mathrm{X}$ data can be correlated with data variable $\mathrm{Y}$. The research constellation can be seen in figure 1 .

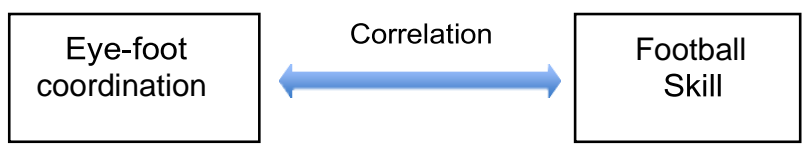

Figure 1 Research constellation.

The samples in this study were Persati Football Club junior players, Aceh Tamiang Regency, aged under 15, totalling 36 players. The measurement instrument used for each variable is (1). Eye foot coordination using the "Football Wall Volley Test" [9], (2) Football skills using "David Lee Test" [10].

Analysis of research data using the product-moment correlation formula. This formula aims to determine the correlation coefficient between the two variables. calculation and tabulation of data using Microsoft Excel and SPSS

\section{RESULT AND DISCUSSION}

Based on the calculation of the research data for the eye-foot coordination variable, a frequency distribution table was compiled, as shown in table 1.

Table 1. Frequency distribution of eye-foot coordination values

\begin{tabular}{|l|l|l|}
\hline Interval & $\begin{array}{l}\text { Absolute } \\
\text { Frequency }\end{array}$ & $\begin{array}{l}\text { Relative } \\
\text { Frequency (\%) }\end{array}$ \\
\hline $26.99-31.99$ & 2 & 5.56 \\
\hline $32.99-37.99$ & 2 & 5.56 \\
\hline $38.99-43.99$ & 2 & 5.56 \\
\hline $44.99-49.99$ & 12 & 33.33 \\
\hline $50.99-55.99$ & 9 & 25.00 \\
\hline $56.99-61.99$ & 6 & 16.67 \\
\hline $62.99-67.99$ & 3 & 8.33 \\
\hline Total & 36 & 100 \\
\hline
\end{tabular}

Based on the frequency distribution table, the histogram of the research data for the eye-foot coordination variable can be seen in Figure 2 .

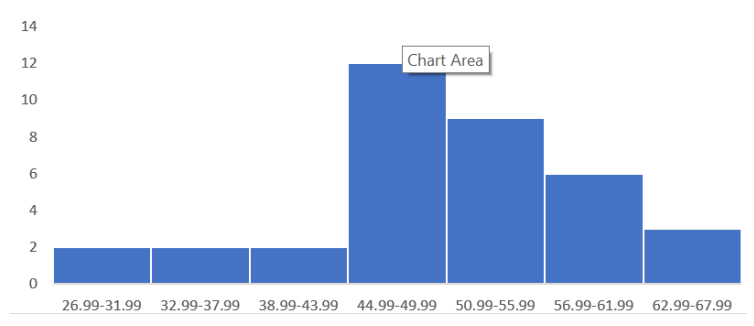

Figure 2 Histogram of eye-foot coordination data.

Based on the calculation of the research data for the football skill variable, a frequency distribution table was compiled, as shown in table 2.

Table 2. Frequency distribution of football skill values

\begin{tabular}{|l|c|l|}
\hline Interval & $\begin{array}{l}\text { Absolute } \\
\text { Frequency }\end{array}$ & $\begin{array}{l}\text { Relative } \\
\text { Frequency (\%) }\end{array}$ \\
\hline $26.99-33.99$ & 2 & 5.56 \\
\hline $34.99-41.99$ & 3 & 8.33 \\
\hline $42.99-49.99$ & 12 & 33.33 \\
\hline $50.99-57.99$ & 13 & 36.11 \\
\hline $58.99-65.99$ & 4 & 11.11 \\
\hline $66.99-73.99$ & 2 & 5.56 \\
\hline Total & 36 & 100 \\
\hline
\end{tabular}

Based on the frequency distribution table, the histogram graph of the research data for the football skill variable can be seen in Figure 3. 
Football Skill

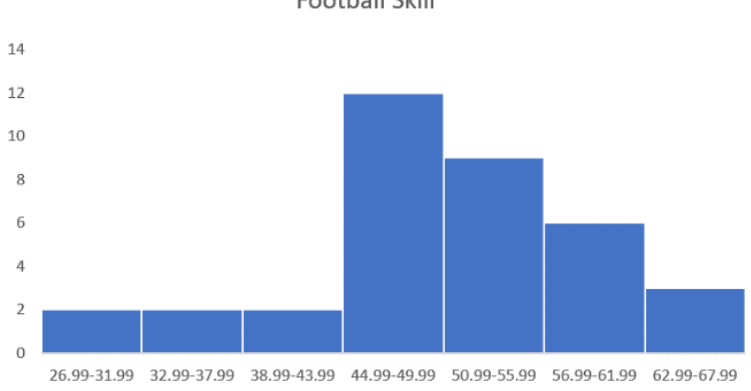

Figure 3 Histogram of football skill data.

Analysis of correlation data showed that the correlation between $\mathrm{X}$ and $\mathrm{Y}$ was 0.74 , with hypothesis testing where $\mathrm{t}$ Count $=6,415>\mathrm{t}$ table $=1.691$ shows a significant correlation between eye-foot coordination and football skills. This means that coordination supports movement skills in a sport, one type of coordination that is important in movement skills includes eye-foot coordination [11]. In football, eyefoot coordination is needed to improve football skills when kicking and dribbling the ball.

Considering the characteristics of football, it can be concluded that the component that must be more dominant in football players is eye-foot coordination. This component can contribute to every player making any movements, such as practising football skills. Football skill is a skill in which a person can coordinate eyesight with foot movements. Athletes who have good coordination are not only able to perform a movement perfectly but also will quickly and easily perform new skills. Good coordination can change and move quickly from one movement pattern to another. Coordination is very important for junior football players to learn. Coordination becomes an exercise so that the right and left brains are balanced [13].

The results of this study are from previous research conducted by Reisi and friends, with research samples of junior football players (same as the sample of this study) and the same research variables. They found that eye-foot coordination affects football skills [14].

\section{CONCLUSION}

Based on the analysis of research data and hypothesis testing, it can be concluded that there is a significant relationship between eye-foot coordination and football skills with a correlation value $(r=0,74$, eyefoot coordination with a correlation value $(r=0,74$, eye-foot coordination contributes $53,29 \%$ to football skills. This research is certainly not free from weaknesses. The weakness is the lack of control over the independent variables. As for further researchers who plan to conduct the same research, they can conduct experimental research to determine the effect of eye-foot coordination on football skills.

\section{AUTHORS' CONTRIBUTIONS}

All the authors developed the research design, Razali conducted experiments, analyzed data and wrote papers. All authors contributed to the revision of the manuscript. All authors agree to the final version of the manuscript and are responsible for the content of the article

\section{ACKNOWLEDGMENTS}

This paper and research would not have been possible without the extraordinary support from the academic community of Syiah Kuala University and Ocean University, as well as the support of the Persati Aceh Tamiang football academy which has allowed its players to be used as research samples and the field as a place for research to take place.

\section{REFERENCES}

[1] D. Formenti, A. Rossi, T. Bongiovanni, F. Campa, L. Cavaggioni, G. Albert, "Effects of Non-SportSpecific Versus Sport-Specific Training on Physical Performance And Perceptual Response In Young Football Players," International Journal of Environmental Research and Public Health 18 (4) (2021) 1-11. DOI: 10.3390/ijerph18041962.

[2] Ł. Oleksy, A. Mika, I. Sulowska-Daszyk, D. Szymczyk, M. Kuchciak, A. Stolarczyk, ... and R. Kielnar, "Standard RTS criteria effectiveness verification using FMS, Y-balance and TJA in footballers following ACL reconstruction and mild lower limb injuries," Scientific Report 11 (1) (2021) 1-9, 2021. DOI: 10.1038/s41598-021-81152-4.

[3] M. Romann, M. Javet, S. Cobley, and D. P. Born, "How relative age effects associate with football players' market values: Indicators of losing talent and wasting money," Sports 9 (7) (2021) 1-8. DOI: $10.3390 /$ sports 9070099 .

[4] D. Murr, P. Larkin, and O. Höner, "Decisionmaking skills of high-performance youth soccer players: Validating a video-based diagnostic instrument with a soccer-specific motor response", Journal of Exercise and Sport Research 51 (1) (2021) 102-111. DOI: 10.1007/s12662-020-006872 .

[5] B. Stankiewicz, M. Cieślicka, S. Kujawski, E. Piskorska, T. Kowalik, J. Korycka and A. Skarpańska-Stejnborn, "Effects of antioxidant supplementation on oxidative stress balance in young footballers- a randomized double-blind 
trial," Journal of the International Society of Sports Nutrition 18 (1) (2021) 1-11. DOI: 10.1186/s12970-021-00447-z.

[6] R. Fernández-Villarino, "Sustainability in the football industry: An approach to the gap between theoretical formulation and practical application, through the results of the social fair play project", Heliyon 7 (6) (2021). DOI: 10.1016/j.heliyon.2021.e07318.

[7] E. Burhaein, B. K. Ibrahim and R. Pavlovic, "The relationship of limb muscle power, balance, and coordination with instep shooting ability: A correlation study in under-18 football athletes", International Journal of Human Movement and Sports Sciences 8 (5) (2020) 265-270. DOI: 10.13189/saj.2020.080515.

[8] D. Sariati, H. Zouhal, R. Hammami, C. C. Clark, A. Nebigh, M. Chtara, ....and O. B. Ounis, "Association Between Mental Imagery and Change of Direction Performance in Young Elite Soccer Players of Different Maturity Status", Frontiers in Psychology 12 (2021) 1-9. DOI: 10.3389/fpsyg.2021.665508.

[9] J. Fry, J. P. Serbera, and R. Wilson, "Managing performance expectations in association football", Journal of Business Research 135 (2021) 445-453. DOI: 10.1016/j.jbusres.2021.06.052.

[10] D. Darpatova-Hruzewicz and R. T. Book, "Applying a relational lens to ethnographic inquiry: Storied insight into the inner workings of multicultural teams in men's elite football", Psychology of Sport and Exercise 54 (2021) DOI: 10.1016/j.psychsport.2021.101886.

[11] M. Fişne, S. Bardakçı, and S. A. Hasaan, "Foreign ownership and local fans: Turkish football fans' perspective", Physical Culture and Sport 89 (1) (2021) 22-33. DOI: 10.2478/pcssr-2021-0003.

[12] J. Vaughan, C. J. Mallett, P. Potrac, M. A. LópezFelip, and K. Davids, "Football, Culture, Skill Development and Sport Coaching: Extending Ecological Approaches in Athlete Development Using the Skilled Intentionality Framework", Frontiers Psychology 12 (2021) 1-13. DOI: 10.3389/fpsyg.2021.635420.

[13] Sridadi, Tomoliyus, E. A. Septiasari, Parijan, H. Yuliarto, and Ilham, "Effect of technical training using a ball on the dribbling speed for football players aged 10-12 years", International Journal of Human Movement and Sports Sciences 9 (4) (2021) 824-831. DOI: 10.13189/saj.2021.090429.
[14] J. Reisi, S. Lenjannejadian, F. Clemente, and C. C. T. Clark, "Introducing an activity-based balance index for soccer players: A validity and reliability study," Asian Journal Sports Medicine 12 (2) (2021) 1-8. DOI: 10.5812/asjsm. 108903. 